OPEN ACCESS

Edited by: James Rivers,

Oregon State University,

United States

Reviewed by:

Wan-chun Liu,

Colgate University, United States

Matthew Dugas,

Illinois State University, United States

*Correspondence:

Vanina D. Fiorin

vfiorini@ege.fcen.uba.ar; vaninadfiorini@gmail.com

Specialty section:

This article was submitted to

Coevolution

a section of the journa

Frontiers in Ecology and Evolution

Received: 14 June 2021

Accepted: 09 December 2021

Published: 13 January 2022

Citation:

Crudele I, Reboreda JC and Fiorini VD (2022) Preferential Begging Responses of Shiny Cowbirds to the

Conspecific Chatter Call.

Front. Ecol. Evol. 9:725051.

doi: 10.3389/fevo.2021.725051

\section{Preferential Begging Responses of Shiny Cowbirds to the Conspecific Chatter Call}

\author{
Ignacio Crudele, Juan C. Reboreda and Vanina D. Fiorini*
}

Departamento de Ecología, Genética y Evolución, IEGEBA-CONICET, Facultad de Ciencias Exactas y Naturales, Pabellón II Ciudad Universitaria, Universidad de Buenos Aires, Buenos Aires, Argentina

Avian brood parasites lay their eggs into the nests of other species, which incubate them and raise the chicks until their independence. Despite living their early weeks of life surrounded by heterospecifics, young brood parasites have the ability to recognize and associate to conspecifics after independence. It has been proposed that the initial conspecific recognition develops when a young parasite encounters a unique speciesspecific signal that triggers the learning of other aspects of the producer of the signal. For cowbirds (Molothrus spp.), this species-specific signal is hypothesized to be the chatter call. Young birds also could express auditory biases, which in some cases lead to discrimination in favor of conspecific songs. Therefore, the perceptual selectivity for chatters might be also present in nestlings. Our aim was to assess if nestlings of the shiny cowbird ( $M$. bonariensis) present a preferential begging response to conspecific chatter calls. We evaluated if they respond more to the parasitic vocalization than host chicks and if they respond more to the chatter than to heterospecific nonhost calls. We tested shiny cowbird chicks reared by chalk-browed mockingbirds (Mimus saturninus) or house wrens (Troglodytes aedon) and host chicks, as control species. We randomly presented to 6-day-old chicks the following playback treatments: (1) conspecific chatter calls, (2) host calls, used as positive controls, and (3) nonhost calls, used as negative control. We measured if chicks begged during the playback treatments and the begging intensity. When responding to the playback of chatter calls, shiny cowbird chicks begged at a higher frequency and more intensively than host chicks. Shiny cowbird chicks reared by mockingbirds begged more intensively to playbacks of conspecific chatter calls than to host calls, while those reared by wrens begged with a similar intensity to playbacks of conspecific chatter and host calls. On the contrary, wren nestlings begged more intensively to playbacks of the wren call than to chatter calls. Mockingbird nestlings did not beg during any treatment. None of the three species begged during the playback of nonhost calls. Our results show that the chatter call produced a preferential begging response in cowbird nestlings, which may be the beginning of a process of conspecific recognition.

Keywords: Molothrus bonariensis, password hypothesis, brood parasitism, vocal cues, begging 


\section{INTRODUCTION}

Conspecific recognition is essential for animals, as it allows individuals to identify members of their own species, search for pairs, and mate successfully, avoiding fitness cost through misdirected social and reproductive effort. In species whose juveniles are reared by their parents, as mammals and most birds, after an early experience with conspecific adults, individuals learn the characteristics of their own species forming an internal representation of salient phenotypic attributes or recognition template and restrict their social preferences as adults to them (Bateson, 1966; Immelmann, 1975). This mechanism called imprinting (Lorenz, 1937; Bateson, 1966; Salzen, 1998; Ten Cate and Vos, 1999) allows individuals to recognize and prefer conspecifics and is adaptive in different social contexts (Immelmann, 1975).

Evidence in oscine species has indicated an auditory bias for conspecific songs during the nestling phase (reviewed by Wheatcroft and Qvarnström, 2015). For instance, Shizuka (2014) found that nestlings of the golden-crowned sparrow (Zonotrichia atricapilla) produce more vocal responses to conspecific than to playback songs of the heterospecific white-crowned sparrow (Z. leucophrys). Moreover, Bliard et al. (2021) found that nestlings of collared flycatcher (Ficedula albicollis) discriminate song based on conspecific alarm calls. They manipulated song phrases starting with the conspecific alarm call followed by either conspecific or heterospecific song notes and found that nestlings responded similarly to both treatments due to the inclusion of the call. This early song discrimination can develop independently of early social experience and depends largely on a genetic component (Wheatcroft and Qvarnström, 2017). For example, Wheatcroft and Qvarnström (2017), manipulated the early social experience of collared and pied flycatchers by swapping young embryos between the nests of two species and found that chicks discriminated in favor of the song of its own species, even when raised by adults from the other species.

Social recognition in interspecific avian brood parasites imposes a paradox. Parasitic nestlings of altricial species are raised by heterospecifics and thus do not have the opportunity to use cues provided from the adults that raise them to learn a conspecific recognition template (Hauber and Sherman, 2001; Slagsvold and Hansen, 2001). Nevertheless, after independence, they interact and reproduce with birds of their own species, which indicates that they have solved the problem of conspecific recognition.

The understanding of the mechanisms involved in the ontogeny of social preferences in brood parasites provides an important challenge to animal behaviorists. Hauber et al. (2001) proposed the "password hypothesis," which states that conspecific recognition in brood parasites is initiated when young encounter some unique species-specific signal or "password" (e.g., a vocalization, behavior, or other characteristic) that triggers learning of additional aspects of the phenotype of the password giver. This hypothesis has been supported by studies conducted in the brown-headed cowbird, Molothrus ater, a generalist broodparasitic species, in which the chatter call seems to be the password for conspecific recognition (Hauber et al., 2001). In this species, the chatter call is the only vocalization given by females, and it is used infrequently by males (Friedmann, 1929; Rothstein et al., 1988). This call is genetically programmed, it does not present geographical variation, and individuals perform it even if they are not exposed to conspecifics (Burnell and Rothstein, 1994). Hauber et al. (2001) found that free-living fledglings and adults of the brown-headed cowbird and also captive fledglings approached to a source-emitting playbacks of chatters more quickly or often than to one emitting vocalizations of heterospecifics (Hauber et al., 2001). They also found that 6day-old nestlings begged more frequently to playbacks of chatters than to other avian sounds and stated that cowbird chicks might have an auditory predisposition for this vocalization. In addition, the chatter call is commonly used by female brownheaded cowbirds in response to song displays of male cowbirds (Burnell and Rothstein, 1994), and it has a fundamental role in shaping behavioral differences on how females interact with preferred males, as the maintenance of the pair bonds is associated with the reciprocal exchange of vocal displays (Kohn, 2018). Neurobiological studies also found an indirect evidence supporting the hypothesis of the chatter call as the password for conspecific recognition in brown-headed cowbirds. Lynch et al. (2017) found that auditory forebrain regions of cowbirds express greater densities of a protein product of the immediateearly gene $Z E N K$ in response to the chatter call relative to control coos of mourning doves (Zenaida macroura). This latter result shows that when cowbirds listen to the conspecific song, they exhibit a specific neural response in brain regions, which are key for social recognition. Moreover, Louder et al. (2019) found that, when acoustically naive juvenile male and female cowbirds were exposed to songs paired with chatter calls, this call enhanced the learning of song production in males and induced a neuro-genomic profile of song familiarity in females, even for heterospecific songs.

The shiny cowbird, M. bonariensis, is an interspecific brood parasite closely related to the brown-headed cowbird (Lanyon, 1992; Johnson and Lanyon, 1999). As the brown-headed cowbird, the shiny cowbird is an extreme generalist that uses more than 250 different hosts (Lowther, 2018). After fledging, shiny cowbird young remains associated with their foster parents for approximately 30-40 days, and, at that time, they join foraging flocks and start roosting with conspecifics (Crudele et al., unpublished data). There is no information on a potential sensory bias allowing for early song discrimination in shiny cowbird young, and no previous studies have determined if the chatter call is recognized for nestlings of this species. To have this information will improve the understanding of the perception components involved in the ontogenetic development of conspecific preferences in obligate brood parasites. Moreover, the study of this new species provides us with the opportunity to test if a potential mechanism to avoid misimprinting is shared by a close relative of the brown-headed cowbird within this parasitic lineage.

In this study, we experimentally evaluated the begging response to different playback treatments of 6-day-old nestlings of shiny cowbirds and two frequent hosts included as control species, namely, the house wren (Troglodytes aedon) and the 
chalk-browed mockingbird (Mimus saturninus). These hosts differ markedly in their behavior during the chick feeding visits. Wrens perform calls when they arrive at the nest to which nestlings seem to respond immediately (Bortolato et al., 2019), whereas mockingbirds do not call upon arrival, and their chicks are stimulated to beg by the movement of the nest (Crudele et al., unpublished data). We determined if shiny cowbird chicks raised by these hosts respond differently to conspecific chatter calls compared with host chicks. We expected that parasitic chicks respond similarly to host chicks when they listen to the adult host playbacks, as they could have learned to respond to this stimulus as their host-mates. For host chicks, we expected that they respond more to conspecific calls than to chatters. Finally, none of the species should respond to nonhost calls as it does not represent a relevant stimulus for them.

\section{MATERIALS AND METHODS}

\section{Study Area}

The field work was carried out during October-February 20182019 and 2019-2020 at Reserve "El Destino" (35 $80^{\prime} 80^{\prime \prime} \mathrm{S}$, $\left.57^{\circ} 82^{\prime} 30^{\prime \prime} \mathrm{W}\right)$, located within the "Parque Costero del Sur" (MAB-UNESCO) in the Province of Buenos Aires, Argentina. The study site comprises patches of native forest dominated by Celtis ehrenbergiana and Scutia buxifolia within a matrix of marshy grasslands and pastures. In this site, shiny cowbird uses as main hosts the chalk-browed mockingbird (frequency of parasitism 70-80\%, Fiorini and Reboreda, 2006; Gloag et al., 2012) and the house wren (frequency of parasitism 50\%, Tuero et al., 2007). In our study area (approximately 155 ha), there are 40-50 territories of chalk-browed mockingbirds, and we put 140 nest boxes that are frequently used by house wrens. From mid-October to the end of January, we searched exhaustively for nests under construction and checked them every day, from the start of laying until the chicks fledged or the nest was abandoned or depredated.

\section{Experiment}

To evaluate the response of chicks to different acoustic stimuli, we tested 68 shiny cowbird chicks ( 42 reared by chalk-browed mockingbirds and 26 reared by house wrens) and 49 host chicks (23 house wrens and 26 mockingbirds) as control species. When nestlings were 6 days of age, they were removed from the nest and placed individually in an artificial nest. To avoid disturbing the parents, the experiment was conducted more than $30 \mathrm{~m}$ from the nest and concealed by vegetation. The artificial nest measured $10 \mathrm{~cm}$ (diameter) $\times 5 \mathrm{~cm}$ (deep) and was located inside a container $(27.5 \mathrm{~cm} \times 21.5 \mathrm{~cm} \times 28 \mathrm{~cm}$; height $\times$ width $\times$ length $)$. To standardize motivation and control for the level of hunger, the nestlings were fed with a wet paste of premium insect food (CéDé) until they were satiated, and then we waited 40 min before starting the playback experiment (Hauber et al., 2001). After that, we walked away $3 \mathrm{~m}$ from the container, and following a silence of $1 \mathrm{~min}$, we started the playback session. We conducted the playback with a Zoom Handy Recorder H4n and video recorded the chick response with a Gopro Hero4 camera. As we only removed the experimental chick from the nest, the rest of the brood remained there, and parents continued normally with their feeding visits. After finishing the experiment, the chick was returned to the nest where it continued with its normal behavior. None of the nests was deserted in association with our manipulation.

We performed the following playback treatments: (1) chatter calls of adult shiny cowbird females, (2) calls of adult host species (mockingbird or wren), and (3) calls of adult nonhost species (saffron finch, Sicalis flaveola), a common species in the study area. The playbacks were presented sequentially in random order, each playback lasted $1 \mathrm{~min}$, and there was an interval of $5 \mathrm{~min}$ between playbacks. To make the playbacks of chatter calls of shiny cowbird and the calls of adult mockingbirds and wrens, we used seven randomly selected vocalizations of six adult individuals of each species recorded in the area during the 2017 breeding season using a Zoom Handy Recorder H4n. Adult wren calls were recorded during their feeding nest visits, when they performed contact calls to nestlings. As mockingbirds do not produce this type of call at the nest, we recorded adult contact calls (Argel de Oliveira, 1989) near the nest. For the playbacks of the nonhost species (saffron finch), we used seven randomly selected vocalizations of seven adult individuals. In this case, the recordings were obtained from https://www.xenocanto.org/species/Sicalis-flaveola and came from individuals that were singing near their nests. The amplitude of the playbacks was standardized with root mean square within and between samples. Figure 1 shows representative spectrograms of the playbacks used in the experiments.

The begging is an unambiguous and easily quantified response behavior that reflects the reaction of nestlings to acoustic stimuli (Hauber et al., 2001). Other behavioral responses as a proxy for paying attention such as "looking" or "moving" were not observed during the recordings of host visits to nests. Therefore, we analyzed the video recordings to determine the following response variables: (1) if the chick responded (i.e., begged) to the playback or not. We considered that the chick begged when it opened the beak during the playback treatment and (2) intensity of begging (begging category for each of the seven calls of the playback treatment). To quantify the intensity of begging, we assigned postural scores using the scale of intensity of Leonard et al. (2003) where: 0 = head down, no gaping; 1 = head down, gaping, sitting on tarsi; 2 = head up, gaping, sitting on tarsi; 3 = same as 2, plus neck stretched upward; $4=$ same as 3, but body lifted off tarsi; and $5=$ same as 4 , plus wings waving. The intensity of begging was determined for nestlings that begged at least once for the seven calls of the playback treatment.

Our experimental work followed the ASAB/ABS Guidelines for the use of animals in research. The study was conducted with the permission of the Provincial Organism for Sustainable Development (OPDS, Buenos Aires, Argentina; permit no. 202/12-OPDS) and complies with the current laws of Argentina.

\section{Comparison of the Calls Used in the Experiment}

To analyze differences in the acoustic structure of the chatter, host, and nonhost calls, we produced spectrograms 


\section{A Shiny cowbird (Chatter)}

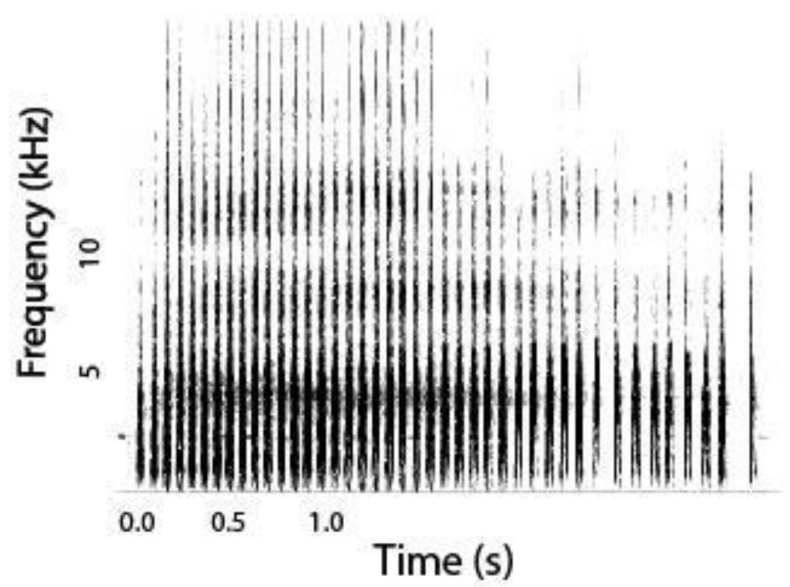

c House wren

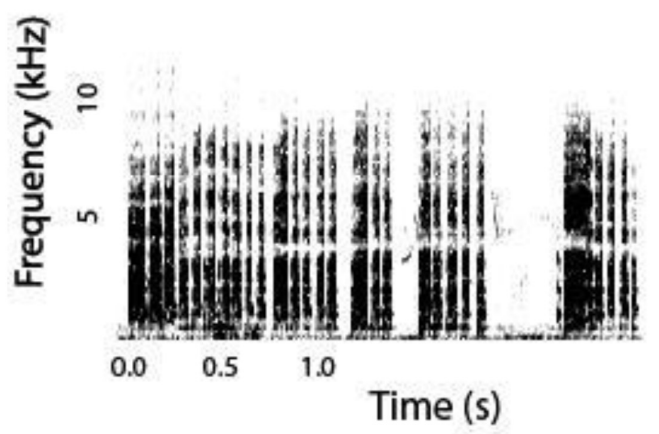

E Shiny cowbird nestling (Begging)

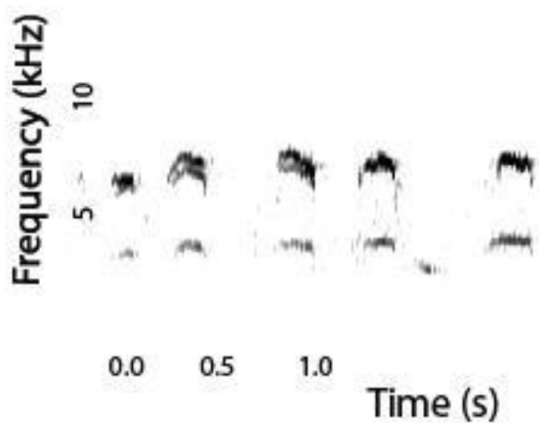

B Chalk-browed mockingbird

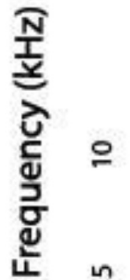

D Saffron finch (Non-host)

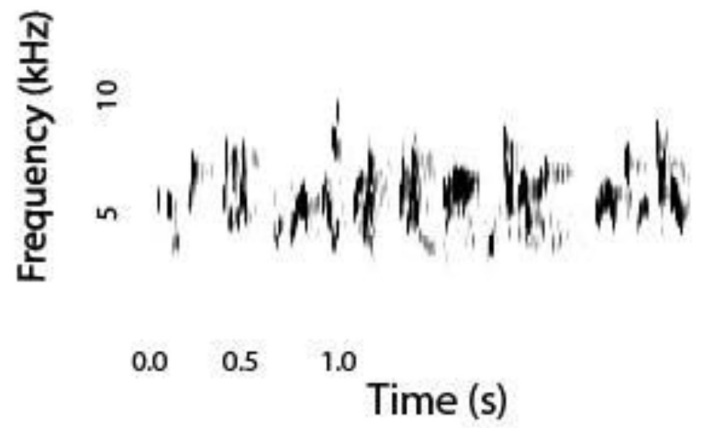

FIGURE 1 | Representative sonograms of the playbacks used in the experiments and of the shiny cowbird begging. (A) Chatter call of a female shiny cowbird (Molothrus bonariensis), (B) call of an adult chalk-browed mockingbird (Mimus saturninus), (C) call of an adult house wren (Troglodytes aedon), (D) call of an adult saffron finch (Sicalis flaveola, i.e., nonhost species), and (E) begging of a shiny cowbird chick.

using RavenPro 1.6.1 (K. Lisa Yang Center for Conservation Bioacoustics, 2019). From the spectrograms, we determined the mean values of five variables (ignoring harmonics): maximum and minimum frequency $(\mathrm{Hz})$, frequency bandwidth $(\mathrm{Hz})$, peak frequency $(\mathrm{Hz})$, and repetition rate (i.e., number of syllables/duration). 


\section{Statistical Analyses}

We analyzed if the frequency of begging (begging as response variable with two levels, yes-no) was affected by (i) chick category: wren, cowbird reared by wrens, and cowbird reared by mockingbirds (as mockingbird chicks never responded to treatments, they did not provide data variability, and we excluded them from the analysis), (ii) playback treatment (host, chatter, and control), the interaction between "chick category" and "playback treatment," and (iii) date of experiment (as changes across the season might influence begging responses). The model also included two random factors, namely nest (as cowbird and host chicks of the same nest were tested) and chick identity nested within nest (as each chick was tested for the three treatments). For this analysis, we performed a generalized linear model (GLMM) with binomial error distribution and logit link function. We also determined if intensity of begging was related to the same predictor variables used for the previous analysis, through a GLMM with negative binomial error distribution and log link function.

After running the models, we found that the interaction between the chick category and playback treatment was significant. Therefore, we performed analyses for each playback treatment (chatter, host, and control) evaluating differences among chick categories and analyses for each chick category (i.e., cowbird reared by wrens, cowbirds reared by mockingbirds, and wrens) evaluating differences among playback treatments, through GLMMs. For each treatment, we evaluated if there were differences among chick categories in (1) the proportion of chicks that begged, through a GLMM with a binomial error distribution and log link function, and (2) the intensity of begging through a GLMM with negative binomial error distribution and log link function. For each chick category, we evaluated if there were differences among treatments in (1) the proportion of chicks that begged through a GLMM with a binomial error distribution and log link function and (2) intensity of begging for each chick category, with a GLMM with a negative binomial error distribution and log link function. The contrasts among categories of chicks and playback treatments were performed using Tukey multiple comparison tests.

To analyze acoustic differences between the vocalizations used in the playback treatments, we performed a principal component analysis (PCA) with the five acoustic variables (maximum and minimum frequency, frequency bandwidth, peak frequency, and repetition rate).

We used the R software, Version 3.4.0 (R Development Core Team, 2013) and the R Studio, Version 1.0.143 (RStudio Team, 2020) and performed the GLM and GLMM analyses using the lme4 package (Bates et al., 2015) and the glmmTMB (Brooks et al., 2017). The PCA analysis was conducted with the Package vegan version $2.5-7$.

\section{RESULTS}

\section{Frequency of Begging}

We did not detect an effect of the date of the experiment (intercept: estimate $\pm \mathrm{SE}=-19.6 \pm 10.9, d f=261, Z=-0.18$,
$P=0.86$; date of experiment: estimate $\pm \mathrm{SE}=-0.004 \pm 0.33$, $Z=0.014, P=0.99)$, but we detected an effect of the interaction between chick category and playback treatment (interaction: $\chi^{2}=74.3, P<0.0001$; chick category: $\chi^{2}=3.37, P=0.2$; playback treatment: $\left.\chi^{2}=100.8, P<0.0001\right)$. Therefore, we performed the analyses for playback treatments separately comparing among chick categories and for chick categories comparing among playback treatments.

When responding to the playback of chatters, the proportion of begging differed among chick categories (GLMM, intercept: estimate $\pm \mathrm{SE}=-1.6 \pm 0.7, d f=87, Z=-2.5, P=0.01$, chick category: $\left.\chi^{2}=14.8, P<0.001\right)$. Cowbird chicks reared by wrens and by mockingbirds begged in a similar proportion (estimate $\pm \mathrm{SE}=-0.7 \pm 0.7, Z=-0.9, P=0.6$ ) and more than wren chicks (cowbird reared by wren vs. wren: estimate $\pm \mathrm{SE}=2.3 \pm 0.8, Z=2.8, P=0.01$ and cowbird reared by mockingbird vs. wren: estimate $\pm \mathrm{SE}=2.9 \pm 0.8, Z=3.5$, $P=0.001$, Table 1). When responding to the playback of the host, the proportion of begging differed among chick categories (GLMM, intercept: estimate $\pm \mathrm{SE}=-0.14 \pm 0.7, d f=87$, $Z=0.2, P=0.8$, chick category: $\left.\chi^{2}=16.3, P=0.0003\right)$. Cowbird chicks reared by mockingbirds begged at a lower proportion than cowbird chicks reared by wrens (estimate $\pm \mathrm{SE}=3.1 \pm 1.0$, $Z=3.0, P=0.008$ ) and wren chicks (estimate $\pm \mathrm{SE}=-3.3 \pm 1.2$, $Z=-2.8, P=0.01$ ), but there were no differences between cowbird reared by wrens and wrens chicks (estimate $\pm \mathrm{SE}=-0.3 \pm 0.9$, $Z=-0.3, P=0.9)$.

Shiny cowbird chicks reared by mockingbirds responded more frequently to conspecific chatter calls (76\%) than to calls of mockingbirds (7\%, GLMM, intercept: estimate $\pm \mathrm{SE}=11.3 \pm 1.9$, $d f=80, Z=6.1, P<0.0001$; playback host: estimate $\pm \mathrm{SE}=-$ $23.8 \pm 2.9, Z=-8.2, P<0.0001$ ), while shiny cowbird chicks reared by wrens responded similarly to conspecific chatter calls and to calls of wrens (65 vs. 50\%, intercept: estimate $\pm \mathrm{SE}=1.4 \pm 0.9, d f=48, Z=1.4, P=0.2$; playback host: estimate $\pm \mathrm{SE}=-1.3 \pm 0.9, Z=-1.5, P=0.1$ ). Wren chicks responded more frequently to wren calls than to shiny cowbird chatter calls (48 vs. $17 \%$, GLMM, intercept: estimate $\pm \mathrm{SE}=-3.2 \pm 2.0, d f=42, Z=1.6, P=0.1$; playback host: estimate $\pm \mathrm{SE}=4.3 \pm 2.2, Z=1.9, P=0.05$ ), while mockingbird chicks did not beg during treatments. None of the three species responded to saffron finch calls (Table 1).

\section{Intensity of Begging}

We did not detect an effect of the date of experiment (intercept: estimate $\pm \mathrm{SE}=-1.1 \pm 0.5, d f=563, Z=-2.1, P=0.04$; date of experiment: estimate $\pm \mathrm{SE}=0.003 \pm 0.002, Z=1.8, P=0.08$ ), but we detected an effect of the interaction between chick category and treatment (interaction: $\chi^{2}=48.4, P<0.0001$, chick category: $\chi^{2}=8.1, P<0.02$, treatment: $\left.\chi^{2}=0.1, P<0.7\right)$. Therefore, we performed the analyses for playback treatments separately comparing among chick categories and for chick categories comparing among playback treatments.

When responding to the playback of chatters, the intensity of begging differed among chick categories (GLMM, intercept: estimate $\pm \mathrm{SE}=-0.5 \pm 0.3, d f=385, Z=-1.7, P=0.1$, chick category: $\left.\chi^{2}=14.7, P=0.0006\right)$. Cowbird chicks 
TABLE 1 | Number of nestlings of each chick category that begged over the total number of nestlings for the different playback treatments.

\begin{tabular}{|c|c|c|c|c|}
\hline Playback treatment & Shiny cowbird reared by mockingbird & Shiny cowbird reared by wren & Mockingbird & Wren \\
\hline Chatter & $32 / 42$ (76\%) & $17 / 26(65 \%)$ & 0/26 (0\%) & 4/23 (17\%) \\
\hline Mockingbird & $3 / 42$ (7\%) & - & 0/26 (0\%) & - \\
\hline Wren & - & $13 / 26(50 \%)$ & - & $11 / 23(48 \%)$ \\
\hline Saffron finch & $0 / 42(0 \%)$ & $0 / 26(0 \%)$ & $0 / 26(0 \%)$ & $0 / 23(0 \%)$ \\
\hline
\end{tabular}

The percentage of responses is shown between parentheses.

reared by mockingbirds begged with a higher intensity than cowbirds reared by wrens (estimate $\pm \mathrm{SE}=-0.8 \pm 0.2$, $Z=-3.0, P=0.006$, Figure 2) and more than wren chicks (estimate $\pm \mathrm{SE}=1.3 \pm 0.3, Z=3.8, P=0.0001$ ), but there were no differences between cowbirds reared by wrens and wrens chicks (estimate $\pm \mathrm{SE}=0.5 \pm 0.6, Z=1.5, P=0.3$, Figure 2). When listening to the playback of the host, the intensity of begging differed among chick categories (GLMM, intercept: estimate $\pm \mathrm{SE}=0.5 \pm 0.2, d f=176, Z=-2.8, P<0.005$, chick category: $\left.\chi^{2}=7.9, P<0.01\right)$. Cowbird chicks reared by mockingbirds begged with a greater intensity than cowbird chicks reared by wrens (estimate $\pm \mathrm{SE}=1.4 \pm 0.6, Z=2.4, P=0.04$,

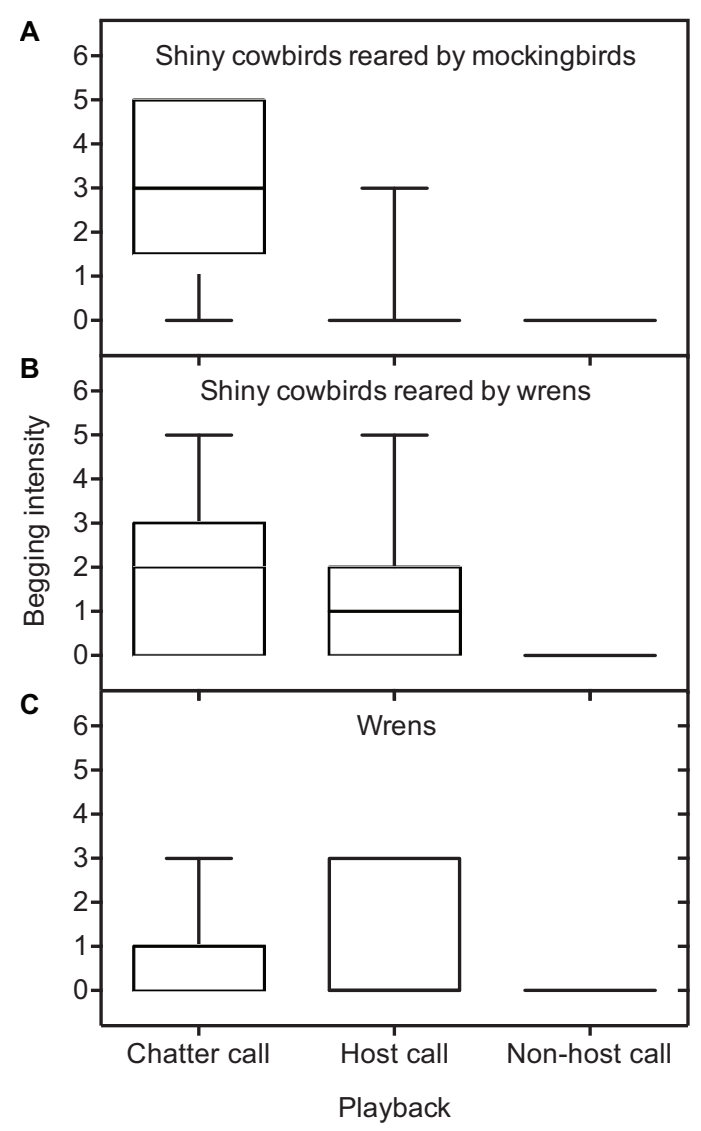

FIGURE 2 | Intensity of the begging response of the three chick categories for different playback treatments (chatter, host, and nonhost playbacks): (A) shiny cowbirds reared by mockingbirds, $(\mathbf{B})$ shiny cowbirds reared by wrens, and (C) wrens. Boxplots show medians, interquartiles, and ranges.
Figure 2) and wren chicks (estimate $\pm \mathrm{SE}=-1.6 \pm 0.6, Z=-2.8$, $P<0.01)$ and cowbirds reared by wrens begged with a similar intensity than wren chicks (estimate $\pm \mathrm{SE}=-0.2 \pm 0.2, Z=-0.9$, $P=0.6$, Figure 2).

Shiny cowbird chicks reared by mockingbirds begged more intensively when they listened a conspecific chatter call than when they listened a mockingbird call (intercept: estimate $\pm \mathrm{SE}=0.8 \pm 0.1, d f=232, Z=5.9, P<0.0001$; playback host: estimate $\pm \mathrm{SE}=-2.2 \pm 0.5, Z=-4.4, P<0.0001)$, while shiny cowbirds chicks reared by wrens showed a similar intensity of begging when they listened a conspecific chatter and a wren call (intercept: estimate $\pm \mathrm{SE}=0.1 \pm 0.2$, $d f=212, Z=0.7$, $P=0.5$; playback host: estimate $\pm \mathrm{SE}=0.2 \pm 0.1, Z=-1.4$, $P=0.2$ ). Finally, wren chicks begged more intensively when they responded to a wren call than a shiny cowbird chatter call (intercept: estimate $\pm \mathrm{SE}=-0.5 \pm 0.4, d f=114, Z=-1.1, P=0.3$; playback host: estimate $\pm \mathrm{SE}=0.5 \pm 0.2, Z=2.4, P=0.01$; Figure 2).

\section{Analysis of the Acoustic Variables}

A PCA biplot of the acoustic variables showed differences among shiny cowbird chatter, mockingbird, wren, and saffron finch calls. PC1 and PC2 explained 64.52 and 17.24\% of the total variation of the data, respectively. Considering loadings above 0.5 , maximum frequency, minimum frequency, peak frequency, and bandwidth were the variables that contributed more to group differentiation along PC1. Shiny cowbird chatter and wren calls were relatively similar and showed a higher bandwidth than the others. Saffron finch calls differ from the other vocalizations in maximum, minimum, and peak frequency (Figure 3). The repetition rate was the variable that contributed more to differentiation along PC2, with shiny cowbird chatter call showing more repetition rate than mockingbird call (Figure 3).

\section{DISCUSSION}

Our results show that shiny cowbird chicks have preferential begging responses to conspecific chatter calls compared with host chicks. When listening to the conspecific vocalizations, parasitic chicks begged at a higher proportion (65-76\%) than host chicks $(0-17 \%)$ and cowbirds reared by wrens also begged more intensively than wren chicks. Although our experiment does not provide direct evidence for the hypothesis of password recognition, as this would require testing cowbirds at an age where they are more likely associated with adult cowbirds (i.e., after fledging), it provides evidence that the chatter call triggers 


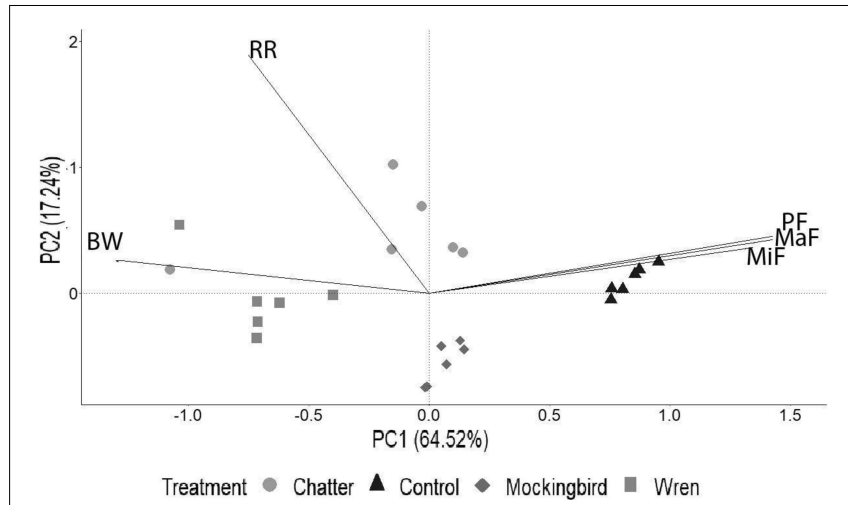

FIGURE 3 | Principal components analysis biplot of acoustic variables used in the playback treatments (shiny cowbird chatter call and wren, mockingbird, and saffron finch adult calls). The first and second principal components were plotted in an $x-y$ plane and accounted for 64.52 and $17.24 \%$, respectively, of the total variance. BW, bandwidth; RR, repetition rate; MiF, minimum frequency; MaF, maximum frequency; PF, peak frequency.

preferential begging responses in shiny cowbird nestlings. If this early preference for the conspecific chatter call continues after cowbirds fledge, it may favor the association of cowbird young with individuals of their own species at the time they became independent from their foster parents, allowing them to develop a conspecific recognition template (Dooling and Searcy, 1982; Whaling et al., 1997; Hauber et al., 2001).

We expected that when cowbirds listened to their host vocalization, they beg similarly to host chicks, as they could have learned to recognize adult host calls during the nestling phase (Tuero et al., 2016). In the case of cowbirds reared by wrens, they begged at a high and similar frequency and intensity than wren chicks supporting the prediction for a positive control. In contrast, wren chicks showed a lower frequency and intensity of begging when they listened to the parasitic chatter call than the call of their own species, which would indicate that their response is species-specific. Cowbird chicks reared by mockingbirds also behaved similarly to host chicks, both showing a low frequency and intensity of begging to mockingbird calls. These results were initially surprising because we expected a stronger response for chicks of both species to the mockingbird call treatment. Nevertheless, we observed through video recordings of $60 \mathrm{~h}$ in 20 nests that adult mockingbirds approached silently to the nest when feeding nestlings (Crudele et al., unpublished data), and chicks seemed stimulated for the vibrations of branches or the nest when adults perched on them instead of for vocalizations of parents. Moreover, during the first experimental sessions, we noted that mockingbird chicks did not beg when listened to the playbacks. We tested if they responded to a vibration of the nest or to a change of the light passing the hand over them, simulating the arrival of the adult to the nest, and all the chicks begged during this stimulus ( $N=11$ chicks). The lack of begging of cowbirds when listening the mockingbird playback differed from the results found by Rivers $(2007,2009)$, in a study in the brownheaded cowbirds parasitizing a taxonomically similar large host, the Brown Thrasher, Toxostoma rufum. These authors found that parasitic chicks begged readily to a wide range of stimuli in the presence of adults and even when adults were absent (Rivers, 2007, 2009). This difference between the responses of closely related cowbird species might have relevance to how cowbird species respond to stimuli and thus conspecific recognition.

As regard the playback of the control nonhost species (i.e., negative control), it did not elicit begging responses in either shiny cowbird or host chicks, indicating that nestlings do not respond to sounds from a species that is not relevant to them.

With respect to the mechanism that could explain the response of cowbird nestlings to the chatter call, one possibility is that cowbird chicks have an auditory predisposition for the conspecific chatter call. This perceptual preference or innate sensory bias could develop in young animals without the need of a previous experience with the stimulus (Bolhuis, 1991) and would lead to a preference for conspecific songs (Bliard et al., 2021). Alternatively, the response to the chatter call could be based on a recognition process known as self-referent phenotype matching (Sherman, 1991; Hauber and Sherman, 2001). In this case, young use some phenotype characteristics of their own (in this case its vocalization) as template for discrimination of individuals they will encounter in the future. Hauber et al. (2001) stated that this explanation would be reasonable in the brown-headed cowbirds due to the similarity between the waveforms and peak frequencies of fledgling begging calls and adult chatters.

There are other alternative hypotheses, apart from the existence of a perceptual selectivity for chatters, that could explain the responsiveness to chatter calls of cowbird nestlings. One possibility is that chatters are like the begging solicitation calls of most important host species (Hauber et al., 2001) and cowbirds respond quickly to be fed. A second hypothesis is that chatters are like vocalizations emitted by the hosts when approaching the nest, such as the case of house wrens. Nevertheless, in this case, it would be expected that also wren chicks respond with a similar frequency and intensity to chatters than to wren calls. However, this was not the case, indicating that these calls are not so similar. A third hypothesis could be that if multiple parasitism is common, stronger begging responses of a cowbird toward the chatter call is due to the close resemblance between the chatter call and the cowbird begging call (i.e., phenotype matching). In this case, the higher begging rate toward the playback of chatter calls is possibly due to the competition among conspecific siblings but not for species recognition. This idea may find support as the begging intensity is lower in cowbirds reared by wrens, where the number of cowbird chicks per parasitized nests is one (Tuero et al., 2007) than in mockingbird nests where the number of parasitic chicks is 1.6 (range 1-4, Fiorini, unpublished data). Nevertheless, in nests of this large host, where cowbird chicks are smaller than host chicks, the food competition, instead of the phenotype matching, seems to modulate the begging that chicks emitted not only to chatter but also to host calls (Tuero et al., 2016).

Our experiment showed that shiny cowbird chicks raised in mockingbird nests responded more frequently and intensively to conspecific chatter calls than to host calls, and cowbird chicks reared by both hosts did not respond to nonhost calls when they were in the host nest. This would indicate that the 
preference for the conspecific chatter call is innate or developed at a very early stage after hatching. Although at that time the parasite chick has no direct contact with adult conspecifics, it could listen the chatter of female cowbirds that are near the nest and eventually see them, which would allow the chick to start learning conspecific characteristics before fledging. In this respect, Soler and Soler (1999) found that adult great spotted cuckoos (Clamator glandarius) visited parasitized nests and had contact with old nestlings and suggested that this behavior could promote imprinting in young cuckoos.

Further experiments must be carried out to assess whether the chatter call, in addition to producing a preferred response in nestlings, is the cue used for juveniles to develop the conspecific template. Preliminary results from an experiment, in which we exposed shiny cowbird juveniles with models and calls of conspecifics and heterospecifics, indicate that young cowbirds develop social preferences with the models paired with the chatter call, no matter what is the model species used (Crudele et al., unpublished data). These results would support that an auditory cue-the chatter-mediates subsequent learning of additional morphological characteristics (Louder et al., 2019).

Although evidence showed that 6-day-old cowbird nestlings respond to conspecific chatter (Hauber et al., 2001, this study), the studies conducted so far have not analyzed whether this acoustic cue produces a neural stimulation in the chicks. The studies that analyzed the expression of genes in the auditory forebrain were performed in adults and juveniles of the brownheaded cowbird (Lynch et al., 2017; Louder et al., 2019). It would be interesting to determine if a neurogenomic response to the chatter call also occurs in nestlings and if the exposure to the password influences neuroplasticity. This would allow us to discern between two alternative hypotheses. The first one, as our results suggest, is that cowbirds are sensitive to the password since they are born. In this case, it could be possible that they have a wide sensitive period to imprint (Immelmann, 1975) that starts during the nestling phase but is consolidated after host independence, when juveniles interact with other cowbirds in conspecific flocks (Han and Fleischer, 1995). The second one is that cowbirds have a delayed imprinting, and they are sensitive to the conspecific cue only after they fledge, when the probability to interact with conspecific increases (Bateson, 1979; O'Loghlen and Rothstein, 1993, 2002).

\section{REFERENCES}

Argel de Oliveira, M. M. (1989). Eco-Etologia do Sabiá-do-Campo Mimus saturninus (Lichtenstein, 1823) PASSERIFORMES, MIMIDAE dissertation, Vol. 71. Brasil: Universidade Estadual de Campinas, 72.

Bates, D., Mächler, M., Bolker, B., and Walker, S. (2015). Fitting linear mixedeffects models using lme4. J. Stat. Softw. 67, 1-48. doi: 10.18637/jss.v06 7.i01

Bateson, P. P. G. (1966). The characteristics and context of imprinting. Biol. Rev. 41, 177-220. doi: 10.1111/j.1469-185x.1966.tb01489.x

Bateson, P. P. G. (1979). How do sensitive periods arise and what are they for? Anim. Behav. 27, 470-486.

Bliard, L., Qvarnström, A., and Wheatcroft, D. (2021). The role of introductory alarm calls for song discrimination in Ficedula flycatchers. Anim. Behav. 177, 241-251. doi: 10.1016/j.anbehav.2021.05.018
In conclusion, our results indicate that shiny cowbird chicks respond differentially to conspecific chatter calls and are consistent with the password hypothesis, adding new evidence to the idea that parasites have a predisposition for conspecific auditory signals that would initiate species recognition.

\section{DATA AVAILABILITY STATEMENT}

The raw data supporting the conclusions of this article will be made available by the authors, without undue reservation.

\section{ETHICS STATEMENT}

The animal study was reviewed and approved by Organismo Provincial para el Desarrollo Sostenible of Buenos Aires Province (Permit number 202/12-O.P.D.S.).

\section{AUTHOR CONTRIBUTIONS}

IC carried out the field work and analyzed the videos. IC and VF performed the data analysis. IC and JR performed the figures. IC, $\mathrm{JR}$, and VF conceived the initial idea, discussed the results, wrote the manuscript, and approved the submitted version.

\section{FUNDING}

This work was supported by grants of the Agencia Nacional de Promoción Científica y Tecnológica and the University of Buenos Aires.

\section{ACKNOWLEDGMENTS}

We are grateful to the editor JR and two reviewers who provided very helpful comments on a previous version of the manuscript. We thank the Elsa Shaw de Pearson Foundation for supporting our fieldwork at Reserva El Destino.

Bolhuis, J. J. (1991). Mechanisms of avian imprinting: a review. Biol. Rev. 66, 303-345. doi: 10.1111/j.1469-185x.1991.tb01145.x

Bortolato, T., Ros, G., Reboreda, J. C., and Fiorini, V. D. (2019). Size matters: shiny cowbirds secure more food than host nestmates thanks to their larger size, not signal exaggeration. Anim. Behav. 157, 201-207.

Brooks, M. E., Kristensen, K., van Benthem, K. J., Magnusson, A., Berg, C. W., Nielsen, A., et al. (2017). "glmmTMB balances speed and flexibility among packages for zero-inflated generalized linear mixed modeling. $R$ J. 9, 378-400.

Burnell, K., and Rothstein, S. I. (1994). Variation in the structure of female brown-headed cowbird vocalizations and its relation to vocal function and development. Condor 96, 703-715. doi: 10.2307/1369473

Dooling, R. J., and Searcy, M. H. (1982). Early perceptual selectivity in the swamp sparrow. Dev. Psychobiol. 13, 499-506. doi: 10.1002/dev.420130508

Fiorini, V. D., and Reboreda, J. C. (2006). Cues used by shiny cowbirds (Molothrus bonariensis) to locate and parasitise chalk-browed mockingbird 
(Mimus saturninus) nests. Behav. Ecol. Sociobiol. 60, 379-385. doi: 10.1007/ s00265-006-0175-3

Friedmann, H. (1929). The Cowbirds. A Study in the Biology of Social Parasitism. Springfield, IL: C. C. Thomas.

Gloag, R., Tuero, D. T., Fiorini, V. D., Reboreda, J. C., and Kacelnik, A. (2012). The economics of nestmate-killing in avian brood parasites: a provisions trade-off. Behav. Ecol. 23, 132-140. doi: 10.1093/beheco/arr166

Han, D. C., and Fleischer, R. C. (1995). DNA fingerprint similarity between female and juvenile brown-headed cowbirds trapped together. Anim. Behav. 49, 1577-1580. doi: 10.1016/0003-3472(95)90079-9

Hauber, M. E., Russo, S. A., and Sherman, P. W. (2001). A password for species recognition in a brood-parasitic bird. Proc. R. Soc. Lond. B 268, 1041-1048. doi: $10.1098 / \mathrm{rspb} .2001 .1617$

Hauber, M. E., and Sherman, P. W. (2001). Self-referent phenotype matching: theoretical considerations and empirical evidence. Trends Neurosci. 24, 609616. doi: 10.1016/s0166-2236(00)01916-0

Immelmann, K. (1975). Ecological significance of imprinting and early learning. Annu. Rev. Ecol. Syst. 6, 15-37. doi: 10.1007/s10071-012-0514-x

Johnson, K. P., and Lanyon, S. M. (1999). Molecular systematics of the grackles and allies, and the effect of additional sequence (CYT B and ND2). Auk 116, 759-768. doi: 10.2307/4089336

K. Lisa Yang Center for Conservation Bioacoustics (2019). Raven Pro: Interactive Sound Analysis Software (Version 1.6.1) [Computer software]. Ithaca, NY: The Cornell Lab of Ornithology.

Kohn, G. M. (2018). Female vocalizations predict reproductive output in brownheaded cowbirds (Molothrus ater). PLoS One 13:e0202067. doi: 10.1371/journal. pone. 0202067

Lanyon, S. M. (1992). Interspecific brood parasitism in blackbirds (Icterinae): a phylogenetic perspective. Science 255, 77-79. doi: 10.1126/science.1553533

Leonard, M. L., Horn, A. G., and Parks, E. (2003). The role of posturing and calling in the begging display of nestling birds. Behav. Ecol. Sociobiol. 54, 188-193. doi: 10.1016/j.yhbeh.2007.08.009

Lorenz, K. (1937). The companion in the bird's world. Auk 54, 245-273.

Louder, M. I. M., Balakrishnan, C. N., Louder, A. A. N., Driver, R. J., London, S. E., and Mark, E. (2019). An acoustic password enhances auditory learning in juvenile brood parasitic cowbirds. Curr. Biol. 29, 1-7. doi: 10.1016/j.cub.2019. 09.046

Lowther, P. E. (2018). Lists of Victims and Hosts of the Parasitic Cowbirds (Molothrus). Available online at: https://www.fieldmuseum.org/sites/default/ files/cowbird-hosts-05sep2018.pdf. (accessed Sep 5, 2018).

Lynch, K. S., Gaglio, A., Tyler, E., Coculo, J., Louder, M. I. M., and Hauber, M. E. (2017). A neural basis for password-based species recognition in an avian brood parasite. J. Exp. Biol. 220, 2345-2353. doi: 10.1242/jeb.158600

O'Loghlen, A. L., and Rothstein, S. I. (1993). An extreme example of delayed vocal development: song learning in a population of wild brown-headed cowbirds. Anim. Behav. 46, 293-304. doi: 10.1006/anbe.1993.1190

O'Loghlen, A. L., and Rothstein, S. I. (2002). Ecological effects on song learning: delayed development is widespread in wild populations of brown-headed cowbirds. Anim. Behav. 63, 475-486. doi: 10.1006/anbe.2001.1951

R Development Core Team (2013). R: A Language and Environment for Statistical Computing. Vienna: R Foundation for Statistical Computing.

Rivers, J. W. (2007). Nest mate size, but not short-term need, influences begging behavior of a generalist brood parasite. Behav. Ecol. 18, 222-230. doi: 10.1093/ beheco/arl068
Rivers, J. W. (2009). Parent-absent begging in the Brown-headed Cowbird (Molothrus ater): the role of short-term need and nestmate size. Behav. Ecol. Sociobiol. 63, 707-717. doi: 10.1007/s00265-008-0704-3

Rothstein, S. I., Yokel, D. A., and Fleischer, R. C. (1988). The agonistic and sexual functions of vocalizations of male brown-headed cowbirds, Molothrus ater. Anim. Behav. 36, 73-86.

RStudio Team (2020). RStudio: Integrated Development for R. Boston, MA: RStudio, PBC.

Salzen, E. A. (1998). "Imprinting," in Comparative Psychology, eds G. Greenberg and M. M. Haraway (New York, NY: Garland), 566-575.

Sherman, P. W. (1991). Multiple mating and kin recognition by self-inspection. Ethol. Sociobiol. 12, 377-386. doi: 10.1016/0162-3095(91)90032-1

Shizuka, D. (2014). Early song discrimination by nestling sparrows in the wild. Anim. Behav. 92, 19-24. doi: 10.1016/j.anbehav.2014.03.021

Slagsvold, T., and Hansen, B. T. (2001). Sexual imprinting and the origin of obligate brood parasitism in birds. Am. Natural. 158, 354-367. doi: 10.1086/32 1994

Soler, M., and Soler, J. J. (1999). Innate versus learned recognition of conspecifics in great spotted cuckoos Clamator glandarius. Anim. Cogn. 2, 97-102.

Ten Cate, C., and Vos, D. R. (1999). Sexual imprinting and evolutionary processes in birds: a reassessment. Adv. Study Behav. 28, 1-31. doi: 10.1016/s00653454(08)60214- 4

Tuero, D. T., Fiorini, V. D., and Reboreda, J. C. (2007). Effects of shiny cowbird Molothrus bonariensis parasitism on different components of house wren Troglodytes aedon reproductive success. IBIS 149, 521-529. doi: 10.1111/j.1474919x.2007.00676.x

Tuero, D. T., Gloag, R., and Reboreda, J. C. (2016). Nest environment modulates begging behavior of a generalist brood parasite. Behav. Ecol. 27, 204-210. doi: 10.1093/beheco/arv140

Whaling, C. S., Solis, M. M., Doupe, A. J., Soha, J. A., and Marler, P. (1997). Acoustic and neural bases for innate recognition of song. Proc. Natl. Acad. Sci. U.S.A. 94, 12694-12698. doi: 10.1073/pnas.94.23.12694

Wheatcroft, D., and Qvarnström, A. (2015). A blueprint for vocal learning: auditory predispositions from brains to genomes. Biol. Lett. 11:20150155. doi: 10.1098/rsbl.2015.0155

Wheatcroft, D., and Qvarnström, A. (2017). Genetic divergence of early song discrimination between two young songbird species. Nat. Ecol. Evol. 1:0192.

Conflict of Interest: The authors declare that the research was conducted in the absence of any commercial or financial relationships that could be construed as a potential conflict of interest.

Publisher's Note: All claims expressed in this article are solely those of the authors and do not necessarily represent those of their affiliated organizations, or those of the publisher, the editors and the reviewers. Any product that may be evaluated in this article, or claim that may be made by its manufacturer, is not guaranteed or endorsed by the publisher.

Copyright (c) 2022 Crudele, Reboreda and Fiorini. This is an open-access article distributed under the terms of the Creative Commons Attribution License (CC BY). The use, distribution or reproduction in other forums is permitted, provided the original author(s) and the copyright owner(s) are credited and that the original publication in this journal is cited, in accordance with accepted academic practice. No use, distribution or reproduction is permitted which does not comply with these terms. 